\title{
The Etiology, Therapy Outcomes and Clinical Predictors among Patients Attending Low Vision Clinics at a tertiary Ophthalmic Referral Center in Tanzania
}

\author{
Chabane P Amisse ${ }^{1 *}$, J Hoffman ${ }^{1,2}$ and William Makupa ${ }^{1,2}$ \\ ${ }^{1}$ Ophthalmology Department, KCMU-College, Moshi, Tanzania \\ ${ }^{2}$ International Centre for Eye Health, London School of Hygiene and Tropical \\ Medicine, London, United Kingdom \\ *Corresponding Author: Chabane P Amisse, Ophthalmology Department, \\ KCMU-College, Moshi, Tanzania.
}

Received: March 07, 2020

Published: April 30, 2020

(C) All rights are reserved by Radha

Annamalai., et al.

\begin{abstract}
Purpose: To determine the etiology, low vision therapy outcomes and predictors for good clinical outcomes among patients attending low vision therapy at Kilimanjaro Christian Medical Centre.

Methodology: We report a cross-sectional, hospital-based study conducted between September 2018 and June 2019 at Kilimanjaro Christian Medical Centre in northern Tanzania. All patients who attended low vision clinic from 2015 to 2018 were reviewed. Excluded were those who had best corrected visual acuity equal to or better than 6/18, patients younger than 5 years and those with no documentation of diagnosis age and/or sex. Wilcoxon signed rank test was used to assess the visual acuity improvement and logistic regression to find the predictors for good visual outcome.

Results: 408 patients were included in this study, of which 208/408 (51\%) were adults. The 3 leading causes of permanent visual impairment in adults were diabetic retinopathy, 63/208 (30.3\%); glaucoma, 21/208 (10.1\%); and corneal scarring, 16/208 (7.7\%). In children they were oculocutaneous albinism, 80/200 (40\%); amblyopia, 20/200 (10\%); and glaucoma, 15/200 (7.5\%). Good low vision therapy outcome was noted in 151/175 (86.3\%) of patients who had assessment for distance therapy and $113 / 157$ (72\%) in those assessed for near low vision therapy. The presenting best corrected visual acuity (distance or near) and the age of the patients were found to be significant predictors for good visual outcome ( $p<0.001$, for both).

Conclusion: In this study low vision therapy often resulted in good visual outcome. Despite this, visual outcome was dependent on the presenting best corrected visual acuity, meaning those most in need tend not respond. Most causes of permanent visual impairment in our setting are preventable or curable if detected early. This is another reminder that prevention is better than cure. Keywords: Visual Impairment; Tanzania; Blindness
\end{abstract}

\section{Abbreviations}

BCVA: Best Corrected Visual Acuity; IQR: Interquartile Range; KCMC: Kilimanjaro Christian Medical Center; logMAR: logarithm of Minimal Angle of Resolution; LVC: Low Vision Clinic; LVT: Low Vision Therapy; VA: Visual Acuity

\section{Introduction}

Permanent visual impairment is an irreversible reduction of vision, with the remaining visual acuity less than $6 / 18$ or constriction of the visual field to less than 20 degrees around a central fixation point. Permanent visual impairment is subcategorized into low vision (individuals who retain some visual function) and to blindness (those with no visual function). Low vision devices, which are task specific, have been found to be helpful in the management of permanent visually impaired patients. Reading is the main task that low vision devices are used for [1,2].
Visual impairment is a public health problem. It has been documented that in 2015 there were 216.6 million people with moderate to severe visual impairment and 36 million people were classes as blind [3]. Old age and poverty have been identified as the main risk factors, whilst age related macular degeneration, glaucoma and diabetic retinopathy were found as the main causes for irreversible visual impairment, particularly in the developed world [4]. The burden of visual impairment impacts upon the financial, social and personal level of those affected. On the personal level the main implications are poor quality of life and dependence on others for support $[5,6]$.

For the last 15 years Kilimanjaro Christian Medical Centre (KCMC) has being providing low vision services. Nonetheless, there is limited data on the outcome of these services provided to the patients. 


\section{Aim of the Study}

The aim of this study was to identify the causes of permanent visual impairment at KCMC, the low vision therapy (LVT) outcomes and the predictors for good visual outcome.

\section{Patients and Methodology}

This was a cross-sectional, analytical, hospital-based study conducted from September 2018 to June 2019 at the Ophthalmology Department in KCMC. KCMC is a tertiary referral hospital in Northern Tanzania, which serves more than 15 million people. Medical records of patients who had attended low vision clinic (LVC) from 2015 to 2018 were reviewed for inclusion criteria. Patients included were all those who had best corrected visual acuity (BCVA) of less than 6/18. Patients were excluded if they were under 5 years of age or if there was no documentation of age, sex or diagnosis.

Ethical clearance was obtained from the Kilimanjaro Christian Medical College Ethical Review Board (Ref. 2372). The minimum sample size was 75, derived from the formula, from Charan and Biswas(7), assuming that the highest prevalence of visual impairment worldwide in general population is not above $5 \%$ [3].

Data were collected for the eye with better BCVA. The identification of the causes of permanent visual impairment was based on the documented diagnosis and/or the documented anterior and posterior segment examination and the findings from any ancillary investigation. Distance visual acuity was collected in Snellen notation and converted to logMAR by using online Snellen-logMAR Visual acuity Calculator software, available on http://myvisiontest. com/. Near visual acuity was collected in M notation and converted to $\log$ MAR by using Oduntan's $\log \mathrm{MAR} / \mathrm{M} / \mathrm{N}$ converting table [8].

Low vision devices used for distance therapy were telescopes with 2X; 2.5X; 3X; 4X; 6X and 8X magnifying power. For near vision therapy, $2 \mathrm{X}$ dome magnifier; $6 \mathrm{X}$ handheld magnifier; $6 \mathrm{X}$ white LED; $6 \mathrm{X}$ illuminated stand magnifier and $3 \mathrm{X}$ handheld magnifiers were used.

\section{Data analysis}

Patients were categorized by age as children (19 years and below) and adults (20 years and above). Among the adults, those aged 60 years and over, were considered as a separate group due to increased risk factors. Visual impairment was categorized as moderate (Visual acuity of 0.5 to $1.0 \log$ MAR); severe (Visual acuity less than $1 \operatorname{logMAR}$ to $1.3 \log \mathrm{MAR}$ ) and blindness (visual acuity less than $1.3 \log \mathrm{MAR}$ ). Patients assessed for improvement were those who had distance visual acuity better or equal to $2.0 \log$ MAR (counting fingers near). The improvement of the visual acuity after LVT was estimated in numbers of lines (in logMAR units) and resulted from the difference between the visual acuity after LVT and the best corrected visual acuity before LVT. Good distance LVT outcome was considered any improvement in the visual acuity of 3 lines ( 3 log units) or more. Good near LVT outcome was considered improvement to visual acuity better or equal to $0.44 \operatorname{logMAR}$ (can read M1 at 12.7 centimeters or more). SPSS version 20 (IBM, Armonk, NY, USA) was used for data analysis and Microsoft OfficeExcel 2010 (Microsoft, Redmond, VA, USA) for data management. Wilcoxon signed rank test was used to assess the visual acuity improvement. Logistic regression was used to assess the predictors for good low vision therapy outcome. Linear regression was used to assess the relationship between the visual acuity before intervention and the magnitude of improvement. Statistical significance was considered if $\mathrm{p}$ values were less than 0.05 .

\section{Results}

Background characteristics of the participants

A total of 408 patients were enrolled. 231/408 (56.6\%) were male and 208/408 (51\%) were adults. The mean age of children was $12(\mathrm{SD}= \pm 4)$ years and of adults was $51(\mathrm{SD}= \pm 17)$ years. The majority $253 / 408(62 \%)$ of patients had moderate visual impairment (Table 1). The adults (20 years and above) were found to have the most severe forms of visual impairment [22/32 (57.9\%) of severe visual impairment and 80/117 (68.4\%) of blind cases]. Most of the children were students: 154/156 (98.7\%).

\section{Etiology of permanent visual impairment}

The leading causes of permanent visual impairment identified were oculocutaneous albinism 90/408 (22.1\%), diabetic retinopathy $63 / 408$ (15.4\%) and glaucoma 36/408 (8.8\%) (Figure 1). The most common identified causes in children were oculocutaneous albinism 80/200 (40\%), amblyopia 20/200 (10\%), glaucoma $15 / 200$ (7.5\%), non-specific optic neuropathy 13/200 (6.5\%) and corneal scarring 10/200 (5\%). In younger adults $(20$ to 59 years) the most common causes were diabetic retinopathy $36 / 136$ (26.5\%) and corneal scarring 12/136 (8.8\%) (Figure 2), whilst in the subjects aged 60 years and above, diabetic retinopathy $27 / 72$ (37.5\%) and glaucoma $17 / 72$ (23.6\%) were the most common causes (Figure 3).

\section{Low vision therapy outcome}

The distance and near visual acuity (VA) after LVT were better than before LVT (Table 2). 157 patients underwent near LVT and 175 underwent distance LVT. The median distance VA after LVT (0.2 logMAR) was significantly better than the median distance VA before LVT (0.8 $\operatorname{logMAR}), \mathrm{p} \leq 0.001$. The median near VA after LVT (0.35 $\log M A R)$ was significantly better than the median near VA before LVT ( $0.9 \log$ MAR), $\mathrm{p} \leq 0.001$. 
The Etiology, Therapy Outcomes and Clinical Predictors among Patients Attending Low Vision Clinics at a tertiary Ophthalmic Referral Center in Tanzania

\begin{tabular}{|l|c|c|}
\hline \multicolumn{1}{|c|}{ Characteristics } & Frequency & Percentage \\
\hline Age groups (years) & & \\
\hline Children (19 years and bellow) & 200 & 49 \\
\hline Adults (20 to 59 years) & 136 & 33.3 \\
\hline 60 years and above & 72 & 17.6 \\
\hline Sex & & \\
\hline Male & 231 & 56.6 \\
\hline Female & 177 & 43.4 \\
\hline Occupation Category (n= 307) & & \\
\hline Students & 172 & 56 \\
\hline Unemployed & 73 & 23.8 \\
\hline Others & 62 & 20.2 \\
\hline Distance Visual Impairment Category & & \\
\hline Moderate & 253 & 62 \\
\hline Severe & 38 & 9.3 \\
\hline Blind & 117 & 28.7 \\
\hline $\begin{array}{l}\text { Near Visual Impairment Category } \\
\text { (n = 157) }\end{array}$ & & \\
\hline Moderate visual impairment & 44 & 28 \\
\hline Severe visual impairment & 69 & 43 \\
\hline $\begin{array}{l}\text { Profound visual impairment and } \\
\text { blindness }\end{array}$ & & 28 \\
\hline
\end{tabular}

Table 1: Background characteristics of the participants $(n=408)$.

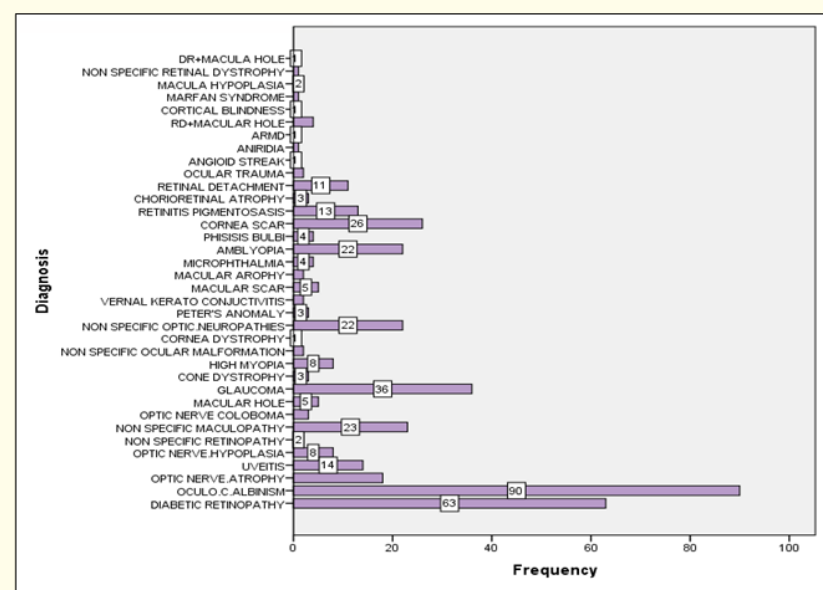

Figure 1: Causes of permanent visual impairment by frequency, among the study subjects $(n=408)$.

Overall, the mean distance VA improvement was 6 logMAR units (SD $\pm 3 \log$ MAR units), however, 18/175 (10.3\%) of the patients had no improvement at all and among the latter ones, 12/18 $(67 \%)$ had VA equal to or worse than $1.8 \log$ MAR. Those who had improvement of 3 or more logMAR units were 151/175 (86.3\%). With regards to near LVT, the median improvement was $5 \log$ MAR

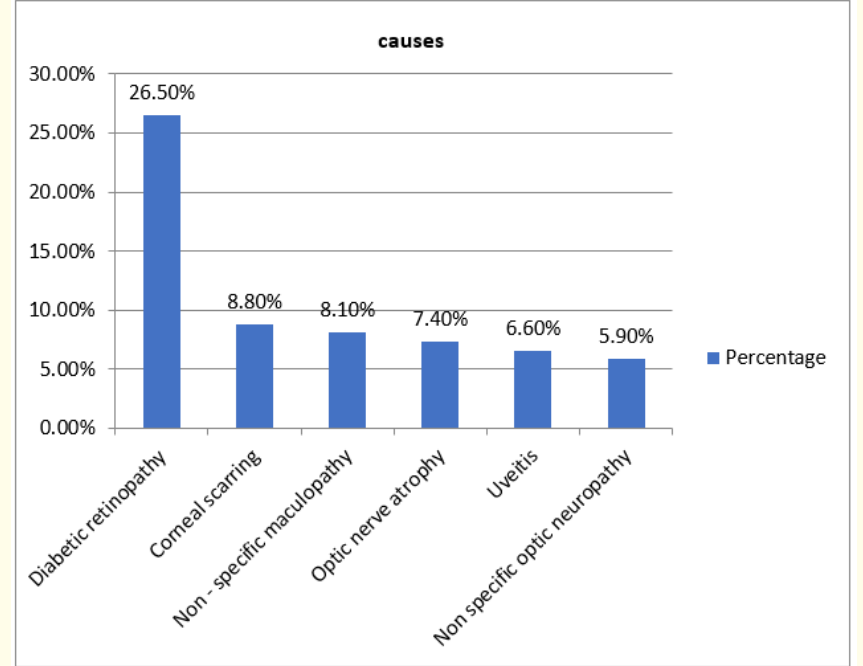

Figure 2: Major causes of permanent visual impairment in adults aged 20 to 59 years old $(n=136)$.

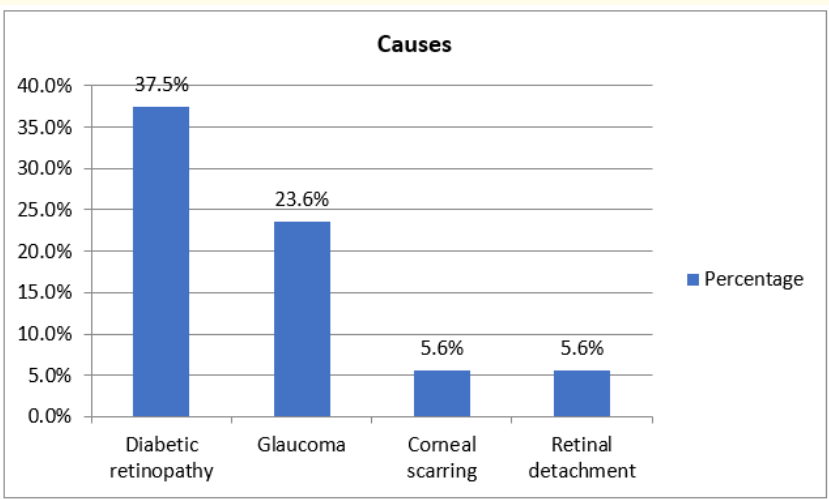

Figure 3: Major causes of permanent visual impairment in patients aged 60 years and more $(n=72)$.

\begin{tabular}{|l|c|c|c|c|}
\hline & $\begin{array}{c}\text { Median vi- } \\
\text { sual acuity } \\
\text { before LVT }\end{array}$ & $\begin{array}{c}\text { Median vi- } \\
\text { sual acuity } \\
\text { after LVT }\end{array}$ & $\begin{array}{c}\text { Amount of } \\
\text { improve- } \\
\text { ment }\end{array}$ & $\begin{array}{c}\text { Average } \\
\text { logMAR units } \\
\text { improved }\end{array}$ \\
\hline $\begin{array}{l}\text { Distance } \\
\text { LVT }\end{array}$ & 0.8 logMAR & $0.2 \log$ MAR & $60 \%$ & $6(\mathrm{SD} \pm 3)^{*}$ \\
\hline Near LVT & $0.9 \log$ MAR & $0.35 \operatorname{logMAR}$ & $55 \%$ & $5(\mathrm{IQR}=6.5)^{* *}$ \\
\hline
\end{tabular}

Table 2: Distance and near low vision therapy (LVT) outcome.

*SD: Standard Deviation; ** IQR: Interquartile Range.

units (IQR = 6.5 logMAR units); however, 8/157 (3.1\%) had no improvement at all. Before LVT only 21/157 (13.4\%) of the patients had near VA better or equal to $0.44 \operatorname{logMAR}$ and only $44 / 157$ (28\%) had near VA better or equal to $0.6 \operatorname{logMAR}$. After LVT on the same patients, $134 / 157$ (85.4\%) of them had near VA equal to or 
The Etiology, Therapy Outcomes and Clinical Predictors among Patients Attending Low Vision Clinics at a tertiary Ophthalmic Referral Center in Tanzania

better than 0.44 and 142/157 (90.4\%) had near VA better than or equal to $0.6 \operatorname{logMAR}$, representing an improvement of $72 \%(85.4 \%$ $-13.4 \%)$ and $62.4 \%(90.4 \%-28 \%)$ respectively.

Predictors for good low vision therapy outcome

In this study we found that the presenting BCVA was a statistically significant predictor for good LVT outcome. The presenting distance BCVA predicts the outcome for the distance LVT. Logistic regression showed that an increase of $0.1 \log$ MAR units in distance visual impairment was associated with a reduction in the odds of having a good outcome in the distance LVT by $91.9 \%$ ( $p \leq 0.001)$, after adjusting for age. We also found that for each one - year in- crease in age, the odds of having good distance LVT outcome was reduced by $7.5 \%$, after adjusting for the distance BCVA (Table 3). Linear regression analysis has shown that the increase of 0.1 logMAR units in the distance visual impairment was associated with decreased improvement of the distance LVT by a factor of 2 logMAR units (95\% C.I. 1 - 2 logMAR units), (P $\leq 0.005)$.

The presenting near BCVA and the distance BCVA predict the near LVT outcome, however, the near BCVA predicts better than the distance BCVA (Table 4). The etiology of visual impairment, the low vision devices used for LVT and the sex, were not found to be statistically significant predictors for the LVT outcome.

\begin{tabular}{|c|c|c|c|c|c|c|c|c|}
\hline \multirow{2}{*}{ Predictor } & \multirow{2}{*}{$\begin{array}{c}\text { Crude Odds } \\
\text { Ratio }\end{array}$} & \multicolumn{2}{|c|}{$\mathbf{9 5 \%}$ CI } & \multirow{2}{*}{ p- value } & \multirow{2}{*}{$\begin{array}{c}\text { Adjusted } \\
\text { Odds Ratio }\end{array}$} & \multicolumn{2}{|c|}{ 95\% CI } & \multirow{2}{*}{ L- value } \\
\cline { 7 - 9 } & & Lower & Upper & & & Upper & \\
\hline Age (years) & 0.901 & 0.872 & 0.931 & $<0.001$ & 0.925 & 0.886 & 0.965 & $<0.001$ \\
\hline Sex & & & & & & & & \\
\hline Male (1) & 1.319 & 0.685 & 2.540 & 0.407 & & & & \\
\hline Distance BCVA* & 0.035 & 0.011 & 0.115 & $<0.001$ & 0.081 & 0.021 & 0.308 & $<0.001$ \\
\hline
\end{tabular}

Table 3: Bivariable and multivariable logistic regression output analysis of predictors for good outcome in distance low vision therapy. ${ }^{*}$ BCVA: Best Corrected Visual Acuity.

\begin{tabular}{|c|c|c|c|c|c|c|c|c|}
\hline \multirow{2}{*}{ Predictor } & \multirow{2}{*}{$\begin{array}{c}\text { Crude Odds } \\
\text { Ratio }\end{array}$} & \multicolumn{2}{|c|}{$95 \% \mathrm{CI}$} & \multirow{2}{*}{ p-value } & \multirow{2}{*}{$\begin{array}{c}\text { Adjusted } \\
\text { Odds Ratio }\end{array}$} & \multicolumn{2}{|c|}{$95 \%$ CI } & \multirow{2}{*}{ p-value } \\
\hline & & Lower & Upper & & & Lower & Upper & \\
\hline Age (years) & 0.980 & 0.959 & 1.002 & 0.077 & & & & \\
\hline \multicolumn{9}{|l|}{ Sex } \\
\hline Male (1) & 1.616 & 0.665 & 3.928 & 0.289 & & & & \\
\hline Near BCVA (logMAR) & 0.198 & 0.102 & 0.386 & $<0.001$ & 0.287 & 0.146 & 0.564 & $<0.001$ \\
\hline Distance BCVA* (logMAR) & 0.018 & 0.03 & 0.109 & $<0.001$ & 0.054 & 0.009 & 0.343 & 0.002 \\
\hline
\end{tabular}

Table 4: Bivariable and multivariable logistic regression output analysis of predictors for good outcome in near low vision therapy

*BCVA: Best Corrected Visual Acuity.

\section{Discussion}

The majority 208/408 (51\%) of the patients attending low vision clinic were aged 20 years and above. This is similar to other studies [9-11], where adults are the most frequent attendees at low vision clinics. However, we report a higher frequency of children in our low vision clinic compared to other studies. This may be due to the fact that we considered all those aged less than 20 years as children, whilst other studies considered children as aged less than 16 years. The majority $172 / 307$ (56\%) of our patients are students. This is likely due to the fact that studying is a vision dependent activity and some patients are referred from nearby blind schools. It could be also due to educated people being more likely to attend low vision clinic as they are better informed. The adults typically present to us at an advanced stage of visual impairment [22/38 (57.9\%) of severe visual impaired and 80/117 (68.4\%) of blind cases]. This may be due to delayed attendance at low vision clinics as well as the differences in the etiology of the visual impairment between both groups.

Most cases of permanent visual impairment attending KCMC are due to oculocutaneous albinism 90/408 (22.1\%), diabetic retinopathy $63 / 408$ (15.4\%), glaucoma 36/408 (8.8\%), corneal scarring 26/408 (6.4\%), non-specific maculopathies 23/408 (5.6\%), amblyopia 22/408 (5.4\%), non-specific optic neuropathies 22/408 (5.4\%) and optic nerve atrophy 18/408 (4.4\%). Glaucoma and corneal scarring are important causes of visual impairment in adults 
and children in our setting. While diabetic retinopathy is the leading cause in all adults, affecting 63/208 (30.3\%), oculocutaneous albinism is leading cause in children, affecting $80 / 200$ (40\%). The high prevalence of diabetic retinopathy among permanent visually impaired adults is possibly due to the high prevalence of diabetic retinopathy in the region [12]. The high prevalence of albinism among our low vision patients could be due to the fact that the blind schools which refer patients to our clinic are referral centers, meaning that visually impaired students come from different parts of the country. It also suggests a high prevalence of albinism within the region and across Tanzania. The findings that oculocutaneous albinism, amblyopia and glaucoma are the leading causes of low vision in children, corroborate with studies done in India [2], Ghana [11] and Nigeria [9]. The high prevalence of diabetic retinopathy among the adults, is similar to studies done in Iran [10] and Turkey [13]. Diabetic retinopathy and glaucoma are the main causes implicated in the group aged 60 years and above in our study, while other countries have reported age related macular degeneration $[9-11,13,14]$. This is the first such study in Tanzania, where age related macular degeneration may be less common than other countries due to different population demographics.

We found a substantial improvement in the average visual acuity with LVT (60\% for distance, 55\% for near LVT). At least $113 / 175$ (64.6\%) of the patients had acquired the minimum visual acuity $(0.56 \pm 0.18 \operatorname{logMAR})$ required in a classroom, after LVT [15]. The number of patients who improved to the visual acuity required for reading books (0.6 logMAR or better) due to LVT was 98/157 (62.4\%) [16]. This is an important achievement. Good LVT outcome was noted in 151/175 (86.3\%) of patients for distance and $113 / 157$ (72\%) of patients for near LVT. Similarly, good outcome results have been documented in studies done in Turkey [13] and Egypt [17].

The presenting distance and near BCVA were found to be the predictors for good LVT outcome for distance and near, respectively. The more severe the presenting visual impairment, the greater the odds of having a poor outcome. These findings are similar to studies performed in Turkey [13] and Egypt [17]. For each increase of one year of age the odds of having good distance LVT outcome are decreased by $7.5 \%$, after adjusting for the presenting distance BCVA. This finding is more likely to be due to adults had high percentages of the severe forms of visual impairment. However, this association was not found in the near low vision therapy. This finding has not been reported quantitatively elsewhere in the literature.
One limitation of this study was the fact that patients included in the analysis for low vision therapy were only those with visual impairment up to 2 logMAR (can count finger near), as clinical experience in our setting suggests that patients are unlikely to respond to LVT at bellow this VA and instead are managed with walking aids. A further limitation is related to missing clinical and demographic information in a number of patient records which may potentially have biased the results.

\section{Conclusion}

Different age groups are affected by different causes of permanent visual impairment in our setting. Nevertheless, glaucoma and corneal scarring are important cause in all age groups. A substantial number of cases of permanent visual impairment can be avoided, treated or the severity reduced, if early detection and management happens. Low vision therapy has good outcomes; however, this is dependent on the severity of the visual impairment. The worse the severity of the visual impairment, the greater is the odds of having a poor outcome. This should be considered by those planning low vision clinics and those intending to refer patients.

\section{Acknowledgments}

We would like to acknowledge the statistical analysis contribution provided by Mr Edwin Musheiguza and Mr. Heavenlight Ayubu Paulo. We also extend our gratitude to Mr. Samwel Ndema, who provided support during the data collection process. A special acknowledgment is to Light for the World, the financial sponsor.

\section{Conflict of Interest}

We have no conflict of interest to disclose.

\section{Bibliography}

1. Özen Tunay Z., et al. "Low Vision Rehabilitation in Older Adults". The Turkish Journal of Ophthalmology 46.3 (2016): 118-122.

2. Ganesh S., et al. "Impact of low vision rehabilitation on functional vision performance of children with visual impairment". Oman Journal of Ophthalmology 6.3 (2013): 170-174.

3. Bourne RRA., et al. "Magnitude, temporal trends, and projections of the global prevalence of blindness and distance and near vision impairment: a systematic review and meta-analysis". The Lancet Global Health's 5.9 (2017): e888-e897.

4. Flaxman SR., et al. "Global causes of blindness and distance vision impairment 1990-2020: a systematic review and meta-analysis". The Lancet Global Health's 5.12 (2017): e1221e1234. 
5. Shah P., et al. "Low vision services: a practical guide for the clinician". Therapeutic Advances in Ophthalmology (2018).

6. Teutsch SM., et al. "Making Eye Health a Population Health Imperative" (2016).

7. Charan J and Biswas T. "How to calculate sample size for different study designs in medical research?" Indian Journal of Psychological Medicine 35.2 (2013): 121-126.

8. Oduntan AO. "A practical logMAR near reference table for low vision practitioners : Design and applications". South African Optometric 65 (2006): 157-162.

9. Olusanya B., et al. "Profile of patients presenting at a low vision clinic in a developing country". BMC Ophthalmology 12 (2012): 31.

10. Ramezani A., et al. "Causes of visual impairment among patients referred to a visual rehabilitation clinic in Iran". Korean Journal of Ophthalmology 26.2 (2012): 80-83.

11. Ackuaku-Dogbe EM., et al. "Causes of low vision and their management at Korle Bu Teaching Hospital, Accra, GHANA". Journal of the West African College of Surgeons 6.3 (2016): 105-122.

12. Stanifer JW., et al. "Prevalence, Risk Factors, and Complications of Diabetes in the Kilimanjaro Region: A Population-Based Study from Tanzania". PLoS One 11.10 (2016): e0164428.

13. Altinbay D., et al. "The Effect of Initial Visual Acuity on Visual Prognosis in Low Vision Aid and Rehabilitation Cases". Ophthalmology and Clinical Research 5.2 (2018).

14. Xia F., et al. "Causes and Three-year Incidence of Irreversible Visual Impairment in Jing-An District, Shanghai, China from 2010-2015". BMC Ophthalmology 17.1 (2017): 216.

15. Negiloni K., et al. "Do school classrooms meet the visual requirements of children and recommended vision standards?" PLoS One (2017).

16. Elliott David and Flanagan John. "Assessment of visual function". Clinicalgate (2015).

17. Shaaban S., et al. "Low vision AIDS provision for visually impaired Egyptian patients - a clinical outcome". Middle East African Journal of Ophthalmology 16.1 (2009): 29-34.

\section{Assets from publication with us}

- Prompt Acknowledgement after receiving the article

- Thorough Double blinded peer review

- Rapid Publication

- Issue of Publication Certificate

- High visibility of your Published work

Website: www.actascientific.com/

Submit Article: www.actascientific.com/submission.php Email us: editor@actascientific.com

Contact us: +919182824667 